\title{
Microstructure of severely deformed metals from X-ray line profile analysis
}

\author{
J. Gubicza ${ }^{1}$, N. H. Nam ${ }^{1}$, K. Máthis ${ }^{2}$ and V. V. Stolyarov ${ }^{3}$ \\ ${ }^{1}$ Department of Solid State Physics, Eötvös University, Budapest, Hungary \\ ${ }^{2}$ Department of Metal Physics, Charles University, Prague, Czech Republic \\ ${ }^{3}$ Institute of Physics of Advanced Materials, Ufa State Aviation Technical University, Ufa, \\ Russia \\ "Contact author; e-mail: gubicza@ludens.elte.hu
}

Keywords: severely deformed metals, line profile analysis, crystallite size, dislocation structure

\begin{abstract}
Two essentially different materials, cubic $\mathrm{Ti}_{49.8} \mathrm{Ni}_{50.2}$ shape memory alloy and hexagonal AZ91 Mg alloy, were deformed by equal channel angular pressing (ECAP). The microstructure developed as a result of severe plastic deformation was studied by X-ray line profile analysis. The correlation between the microstructure and the mechanical behavior was also investigated. Below $100{ }^{\circ} \mathrm{C}$ the tensile strength of the $\mathrm{Mg}$ alloy increased as a consequence of the increase of the dislocation density owing to ECAP. Above $200{ }^{\circ} \mathrm{C}$ the strength decreased and the ductility increased as a result of the breakage of the $\mathrm{Al}_{12} \mathrm{Mg}_{17}$ precipitates due to ECAP. The analysis of the dislocation contrast factors of $\mathrm{Ti}_{49.8} \mathrm{Ni}_{50.2}$ revealed that $<100>\{110\}$ dislocations with $<111>$ line vector formed during ECAP.
\end{abstract}

\section{Introduction}

Severe plastic deformation is an effective tool for producing bulk ultrafine grained (submicron grain sized or nanostructured) metals [1]. One of the most common severe plastic deformation methods is equal channel angular pressing (ECAP) - a technique that results in a homogeneous sub-micron grain structure of the workpiece [1]. The ultrafine-grained materials produced by ECAP have unique mechanical properties, e.g. very high strength at room temperature and good ductility at high temperature [1]. For understanding the mechanical behaviour of materials produced by ECAP it is necessary to characterize their microstructure. $\mathrm{X}$-ray diffraction line profile analysis is a widely used method for studying the microstructure of nanocrystalline materials $[2,3]$. The standard methods of line profile analysis based on the full widths at half maximum, the integral breadths and the Fourier coefficients of the profiles provide the apparent crystallite size and the mean square strain. In severely deformed materials where the lattice distortions are primarily caused by dislocations the mean square strain can be expressed in terms of the characteristic parameters of the dislocation structure [4]. In these formulas the anisotropic strain broadening of the line profiles is taken into account by the contrast factors of dislocations [5]. Since the values of the dislocation 
contrast factors depend on the dislocation slip systems present in the crystal, the evaluation of X-ray line profiles for the contrast factors permits the determination of the dislocation structure [6]. In the last few years, a fast development in computing made it possible to work out procedures for determining the parameters of the microstructure by fitting the whole diffraction profiles [7-9]. In the recently elaborated multiple whole profile (MWP) fitting method, the measured intensity profiles, or their Fourier transforms are fitted by theoretical functions calculated on the basis of a model of the microstructure [9]. This procedure makes it possible to determine both the crystallite size distribution and the dislocation structure in ultrafine grained materials.

In this paper two examples are shown for the effectiveness of X-ray line profile analysis in the study of microstructure of ultrafine grained materials produced by ECAP: a cubic $\mathrm{Ti}_{49.8} \mathrm{Ni}_{50.2}$ shape memory alloy and a hexagonal AZ91 Mg alloy. The correlation between the microstructure and the mechanical properties is also investigated.

\section{Experimental details}

The $\mathrm{Ti}_{49.8} \mathrm{Ni}_{50.2}$ specimen in rod form was annealed at $800{ }^{\circ} \mathrm{C}$ for 1 hour and then it was quenched in water to homogenize the structure and to eliminate the thermomechanical prehistory [10]. The mean grain size of this initial state was $80 \mu \mathrm{m}$. The sample was subsequently deformed in an ECAP die at $450{ }^{\circ} \mathrm{C}$. The diameter of the die channels was $16 \mathrm{~mm}$ and the angle of the intersecting channels was $110^{\circ}$ [10]. The ECAP deformation was repeated up to 8 passes following route $\mathrm{B}_{\mathrm{C}}[1]$.

The main alloying elements in the Mg-based AZ91 alloy are Al (9.1 wt.\%) and $\mathrm{Zn} \mathrm{(0.88}$ wt.\%). The total concentration of other impurities ( $\mathrm{Mn}, \mathrm{Si}, \mathrm{Fe}, \mathrm{Cu}, \mathrm{Ni}$ and $\mathrm{Be}$ ) is less than 0.2 wt.\%. The shape of the specimen was a rectangular parallepipid with $9 \mathrm{~mm}$ in length and cross section of $4 \times 10 \mathrm{~mm}^{2}$. The initial state of the specimen was created by solution heat treatment at $413{ }^{\circ} \mathrm{C}$ for 18 hours. The sample was deformed by 8 ECAP passes at $270{ }^{\circ} \mathrm{C}$ using a $90^{\circ}$ die following route $\mathrm{C}[1]$.

The microstructure of the ECAP treated specimens was investigated by X-ray line profile analysis. The X-ray diffraction profiles were measured on the cross-section perpendicular to the axis of ECAP treatment. The X-ray diffraction experiments were performed using a highresolution diffractometer (Nonius FR591) with rotating $\mathrm{Cu}$ anode $(\lambda=0.15406 \mathrm{~nm})$ and a Ge monochromator. The instrumental broadening $\left(\Delta 2 \Theta=0.006^{\circ}\right)$ was negligible compared to the measured peak broadening $\left(\Delta 2 \Theta=0.1-0.3^{\circ}\right)$ therefore instrumental correction was not performed. The profiles were recorded by a linear position sensitive gas-flow detector (OED 50 Braun, Münich). The peak profiles were evaluated by the MWP fitting procedure described in detail in reference [9]. In this method, the Fourier coefficients of the experimental profiles are fitted by the theoretical Fourier transforms calculated on the basis of a model of the microstructure. In this model, the crystallites have a spherical shape and a log-normal size distribution, and the lattice strains are assumed to be caused by dislocations. The procedure has five or six fitting parameters for cubic or hexagonal crystals, respectively: (i) the median and the variance, $m$ and $\sigma$, of the log-normal size distribution function, (ii) the density and the arrangement parameter of dislocations, $\rho$ and $M$, and (iii) the $q$ (cubic crystals) or $q_{1}$ and $q_{2}$ (hexagonal crystals) parameters in the contrast factors of dislocations. The arithmetic, the area- and the volume-weighted mean crystallite sizes can be calculated from 
$m$ and $\sigma$ using formulas given in reference [7]. In this paper only the volume-weighted mean crystallite size, $\langle x\rangle_{v o l}$ is presented. The $q$ or $q_{1}$ and $q_{2}$ parameters describe the dislocation slip systems present in the specimen.

\section{Results and discussion}

\section{ECAP treated $\mathrm{Ti}_{49.8} \mathrm{Ni}_{50.2}$}

The $\mathrm{Ti}_{49.8} \mathrm{Ni}_{50.2}$ specimen has $\mathrm{B} 2$ cubic structure. The $\mathrm{X}$-ray line profile analysis was carried out only on the fundamental reflections as the superlattice peaks were very weak. The measured (open circles) and the fitted (solid line) Fourier transforms for five fundamental reflections of $\mathrm{Ti}_{49.8} \mathrm{Ni}_{50.2}$ deformed by 8 ECAP passes are shown in figure 1 . The volume-weighted mean crystallite size and the dislocation density obtained from the fitting are $72 \pm 8 \mathrm{~nm}$ and $16 \pm 2 \cdot 10^{14} \mathrm{~m}^{-2}$, respectively. This means that ultrafine grained microstructure is formed from the initial material as a result of ECAP. It has been shown recently by high resolution transmission electron microscopy that $<100>\{110\}$ dislocations with $<111>$ line vector were formed in $\mathrm{Ti}_{50} \mathrm{Ni}_{50}$ during high pressure torsion [11]. The $q$ parameter value of these dislocations in $\mathrm{Ti}_{49.8} \mathrm{Ni}_{50.2}$ was determined by detailed numerical calculations using the equations from [12] and the elastic constants from [13]. This yielded the $q$ value of 2.19 which is in good agreement with the experimental value of $q$ parameter $(2.1 \pm 0.1)$ determined by line profile analysis for ECAP treated $\mathrm{Ti}_{49.8} \mathrm{Ni}_{50.2}$ specimen. This indicates that the dislocations formed during ECAP are $<100>\{110\}$ dislocations with $<111>$ line vector, similarly as in the case of high pressure torsion. Mechanical tests show that ECAP results in the increase of the yield stress (YS) from 600 to $1140 \mathrm{MPa}$ and the ultimate tensile strength (UTS) from 940 to $1240 \mathrm{MPa}$ while the elongation to failure is reduced from 40 to $25 \%$ at room temperature [14]. These changes can be attributed to the large increase of the dislocation density owing to ECAP.

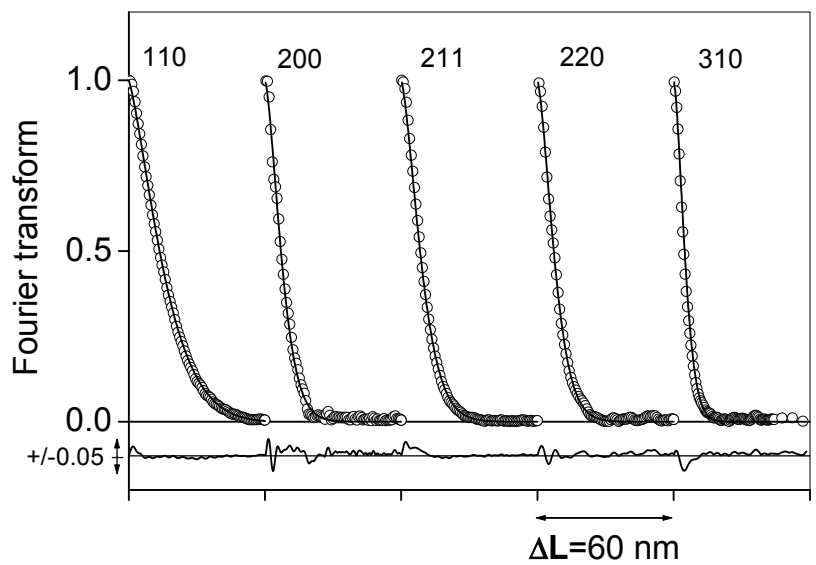

Figure 1. The measured (open circles) and the fitted (solid line) Fourier transforms for $\mathrm{Ti}_{49.8} \mathrm{Ni}_{50.2}$ deformed by 8 ECAP passes. The difference is also shown in the bottom part of the figure. 


\section{AZ91 Mg alloy deformed by ECAP}

X-ray diffraction phase analysis shows that the initial state of AZ91 Mg alloy is a supersaturated solid solution. During high temperature ECAP $\mathrm{Al}_{12} \mathrm{Mg}_{17}$ precipitates are formed. Scanning electron microscopy (SEM) investigations reveal that these precipitates have rod-like shape which breaks into smaller parts owing to severe shear deformation during ECAP [15]. X-ray line profile analysis of the reflections of the Mg alloys shows that ECAP results in the reduction of the crystallite size from $253 \pm 38 \mathrm{~nm}$ to $97 \pm 10 \mathrm{~nm}$ and the increase of the dislocation density from $0.4 \pm 0.1 \cdot 10^{14} \mathrm{~m}^{-2}$ to $2 \pm 0.2 \cdot 10^{14} \mathrm{~m}^{-2}$. The value of the arrangement parameter of dislocations, $M$, obtained from the fitting decreases from 2.5 to 1.6 during ECAP indicating the increase of the dipole character of the dislocation structure.

The $q_{1}$ and $q_{2}$ parameters of the contrast factors depend on the character of dislocations and therefore enable the determination of the prevailing dislocation slip systems in the sample. The $q_{1}$ and $q_{2}$ values for the eleven possible slip systems in Mg according to Kuzel and Klimanek [5] have been calculated and listed in table 2 in reference [16]. The eleven dislocation slip systems can be classified into three groups based on their Burgers vectors: $b_{1}=1 / 3<-2110>$ ( $<\mathrm{a}>$ type), $b_{2}=<0001>(<\mathrm{c}>$ type $)$ and $b_{3}=1 / 3<-2113>(<\mathrm{c}+\mathrm{a}>$ type $)$. A computer program was elaborated to determine the Burgers vector population from the experimental values of $q_{1}$ and $q_{2}$ [17]. There are 4, 2 and 5 slip systems in the $<\mathrm{a}>,<\mathrm{c}>$ and $<\mathrm{c}+\mathrm{a}>$ Burgers vector groups, respectively. The program selects some slip systems from each group and averages their calculated $q_{1}$ and $q_{2}$ values with equal weights. The relative fractions of the Burgers vectors were calculated by making the measured and the weighted averaged theoretical values of $q_{1}$ and $q_{2}$ equal. If the weights have positive values the program stores them as one of the possible solutions. After examining all possible solutions, ranges of the three weights are obtained as the final solution. It was found that in the initial state the relative fractions of the $<\mathrm{a}>,<\mathrm{c}>$ and $<\mathrm{c}+\mathrm{a}>$ Burgers vectors are $68-86 \%, 0-15 \%$ and $0-14 \%$, respectively. The abundance of $\langle\mathrm{a}>$-type dislocations besides the $\langle\mathrm{c}>$ - and $\langle\mathrm{c}+\mathrm{a}>$-type dislocations can be explained by the smallest formation energy of $<\mathrm{a}>$-type dislocations. After high temperature ECAP the relative fractions of the $\langle\mathrm{a}\rangle,\langle\mathrm{c}\rangle$ and $\langle\mathrm{c}+\mathrm{a}\rangle$ Burgers vectors are changed to $54-58 \%, 0-2 \%$ and $38-42 \%$, respectively. It should be noted that for the ECAP treated specimen a weak texture was established in which hexagonal basal planes were parallel to the longitudinal axis of the billet. The effect of this texture on the microstructural parameters determined by X-ray line profile analysis can be neglected as a good agreement was found between the shape of peak profiles obtained from the longitudinal and cross sections. The mechanical behavior of the ECAP treated Mg alloy was studied by tensile test at room temperature, 100, 200 and $300{ }^{\circ} \mathrm{C}$. The tensile measurements took 15-30 min depending on the temperature. After failure of the samples the microstructure was investigated by X-ray line profile analysis at room temperature. The volume-weighted mean crystallite size and the dislocation density are plotted as a function of temperature of deformation in figure 2 . It can be seen that the dislocation density decreases while the crystallite size increases after $100{ }^{\circ} \mathrm{C}$ with increasing temperature because of the recovery of the microstructure. Below $100{ }^{\circ} \mathrm{C}$ the UTS is higher for the ECAP treated specimen than that for the initial state by about $30 \%$. This can be explained by the higher dislocation density developed during ECAP deformation. At the same time above $200{ }^{\circ} \mathrm{C}$ the UTS for the ECAP sample is half of that for the initial state. Moreover, the elongation to failure is 3 and 6 times higher for the ECAP specimen than for the initial state at 200 and $300{ }^{\circ} \mathrm{C}$, respectively. This increase of the ductility 
can be attributed to the breakage of the rod-like $\mathrm{Al}_{12} \mathrm{Mg}_{17}$ precipitates during ECAP which facilitates the dislocation motion necessary for the recovery of the microstructure. The relative fractions of Burgers-vectors obtained on the tensile deformed ECAP samples are plotted as a function of deformation temperature in figure 3 . The increase of the relative fraction of $<\mathrm{c}+\mathrm{a}>$ dislocations can be observed at high temperature $\left(300^{\circ} \mathrm{C}\right)$.

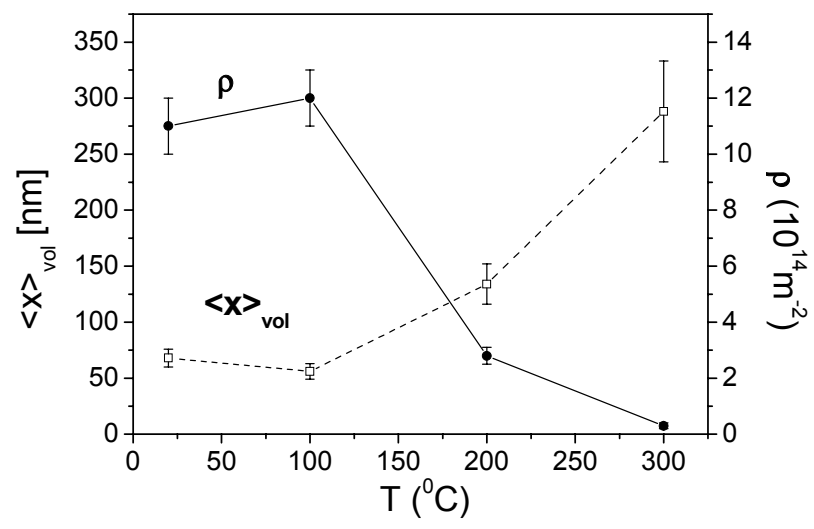

Figure 2. The dislocation density, $\rho$, and the volume-weighted mean crystallite size, $\langle x\rangle_{v o l}$ as a function of temperature of tensile test performed on the ECAP treated Mg alloy. The microstructural data were determined after the failure of the samples.

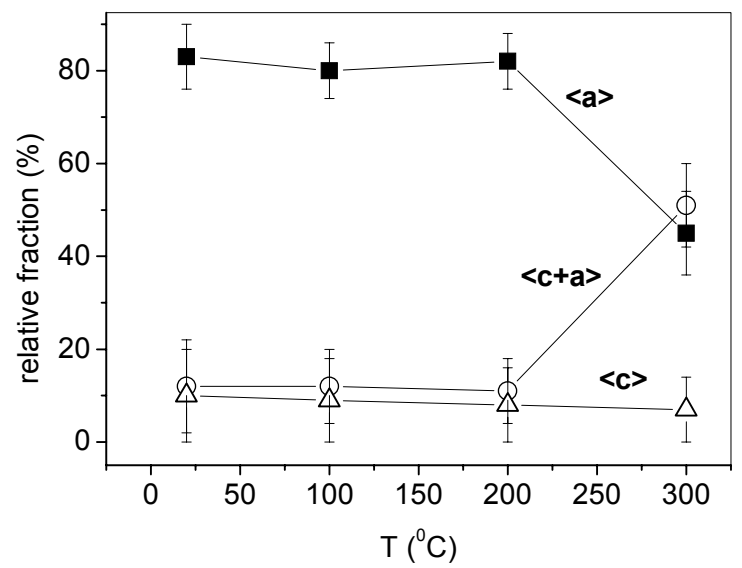

Figure 3. The relative fractions of $\langle a\rangle,\langle c\rangle$ and $\langle c+a\rangle$ dislocations as a function of temperature of tensile test performed on the ECAP treated Mg alloy. 


\section{Conclusions}

The analysis of the anisotropic strain broadening of the diffraction peaks of $\mathrm{Ti}_{49.8} \mathrm{Ni}_{50.2}$ suggests that $<100>\{110\}$ dislocations with $<111>$ line vector are formed during ECAP. The ECAP deformation of AZ91 Mg alloy results in the increase of the dislocation density which causes the increase of the tensile strength below $100{ }^{\circ} \mathrm{C}$. During ECAP the $\mathrm{Al}_{12} \mathrm{Mg}_{17}$ precipitates in AZ91 Mg alloy breaks into smaller parts. This facilitates the recovery of the microstructure under tensile load above $200{ }^{\circ} \mathrm{C}$ which results in the decrease of strength and the increase of ductility compared to the initial state. The analysis of the contrast factors shows the abundance of of $<$ a $>$-type $(1 / 3<-2110>)$ dislocations. During deformation of AZ91 alloy at $300{ }^{\circ} \mathrm{C}$ the relative fraction of $<\mathrm{c}+\mathrm{a}>(1 / 3<-2113>)$ dislocations increases.

\section{References}

1. Stolyarov, V.V., Zhu, Y.T., Alexandrov, I.V., Lowe, T.C. \& Valiev, R.Z., 2003, Mater. Sci. Eng. A, 343, 43.

2. Rafaja, D., Klemm, V., Schreiber, G., Knapp, M. \& Kuzel, R., 2004, J. Appl. Cryst., 37, 613 .

3. Armstrong, N. \& Kalceff, W., 2004, J. Res. Natl. Stand. Technol., 109, 155.

4. Wilkens, M., 1970, Phys. Stat. Sol. (a), 2, 359.

5. Kuzel jr., R. \& Klimanek, P., 1989, J. Appl. Cryst., 22, 299.

6. Kamminga, J.-D. \& Delhez, R., 2001, Mater. Sci. Eng. A, 309-310, 55.

7. Langford, J.I., Louër, D. \& Scardi, P., 2000, J. Appl. Cryst., 33, 964.

8. Scardi, P. \& Leoni, M., 2002, Acta Cryst. A, 58, 190.

9. Ungár, T., Gubicza, J., Ribárik, G. \& Borbély, A., 2001, J. Appl. Cryst. 34, 298.

10. Pushin, V.G., Stolyarov, V.V., Valiev, R.Z., Kourov, N.I., Kuranova, N.N., Prokofjev, E.A. \& Yurchenko, L.I., 2002, Annales de Chimie - Science des Materialux, 27, 77.

11. Rentenberger, C., Waitz, T., \& Karnthaler, H.P., 2004, Scripta Mater., 51, 789.

12. Ungár, T., Dragomir, I., Révész, Á. \& A. Borbély, 1999, J. Appl. Cryst., 32, 992.

13. Ren, X., Miura, N., Zhang, J., Otsuka, K., Tanaka, K., Koiwa, M., Suzuki, T., Chumlyakov, Yu.I. \& Asai, M., 2001, Mater. Sci. Eng. A, 312, 196.

14. Stolyarov, V., Prokofiev, E., Prokoshkin, S., Dobatkin, S., Trubitsyna, I., Khmelevskaya, I., Pushin, V., Zhu Y.T. \& Valiev, R.Z., Acta Mater., in preparation.

15. Máthis, K., Gubicza, J., \& Nam, N.H, J. All. Comp. 2005, 394, 194.

16. Dragomir, I.C. \& Ungár, T., J. Appl. Cryst. 2002, 35, 556.

17. Máthis, K., Nyilas, K., Axt, A., Dragomir, I., Ungár, T. \& Lukáč, P., 2004, Acta Mater., 52, 2889.

Acknowledgements. This research was supported by Hungarian National Scientific Research Fund (OTKA) under contract numbers T-042714, T-043247 and F-047057. 